\title{
Effect of Incorporation of Self-Healing Microcapsules to Experimental Resin Composite on Some Mechanical Properties
}

\author{
Passant S. Abdel Hameed ${ }^{(1)}$, Inas T. Motawea ${ }^{(2)}$, Hisham Essawy ${ }^{(3)}$, Heba A. Eltayeb $^{(4)}$
}

Codex : 66/1810

azhardentj@azhar.edu.eg

http://adjg.journals.ekb.eg

\section{KEYWORDS}

Self-healing microcapsules, composite

\begin{abstract}
Purpose: The present study aimed to investigate the effect of incorporation of the new Triethylene glycoldimethacrylate and N,N-Bis(2-hydroxyethyl)-p-toluidine (TEGDMA)- (DHEPT) in polyurea formaldehyde (PUF) micro-capsules into an experimental dental resin composite on the flexural strength and fracture toughness and the evaluation of its self- healing efficacy. Materials and Methods:_Polyurea formaldehyde microcapsules were synthesized by insitu polymerization technique, encapsulating a triethylene glycol dimethacrylate and dihydroxy ethyl para toluidine (TEGDMA-DHEPT) as a healing liquid, then experimental composite resin is prepared. Microcapsules are incorporated in the resin composite with concentrations $0 \%$, $2.5 \%, 5 \%, 7.5 \%$ and $10 \%$, then experimental resin composite specimens were fabricated. Fracture toughness and flexural strength were examined by three point loading using universal testing machine till fracture. The fracture toughness was evaluated by using single edge V-notched beam method, self healing efficacy is evaluated as the ratio between the healed fracture toughness and the virgin fracture toughness. Results: Regarding flexural strength results, it was found that the $0 \%$ group has the highest flexural strength while the $10 \%$ group had the lowest flexural strength. On the other hand, on evaluating the results, of $7.5 \%$ group it was found that this concentration did not affect the flexural strength remarkably. Regarding the virgin fracture toughness results, $0 \%$ group has the highest flexural strength, while the $10 \%$ group the lowest flexural strength, specimens were fractured and healed, then fractured again to measure the healed fracture toughness, on examining the results of the healed fracture toughness, it was found that no significant difference between $0 \%$ and $2.5 \%$ as no healing occur at such specimen, Also the results showed that the highest healed fracture toughness was in $5 \%$, followed by $7.5 \%$, followed by $10 \%$. The self-healing efficacy increased to
\end{abstract}

- Paper extracted from master thesis entitled: Effect of Incorporation of Self-Healing Microcapsules to Experimental Resin Composite on Some Mechanical Properties.

1. Demonstrator at Biomaterials Department, Badr university.

2. Associate Professor at Biomaterials Department, Al Azhar university for Girls.

3. Proffessor at polymer chemistry and pigments Department, National Research Center.

4. Lecturer at Biomaterials Department, Al Azhar university for Girls. 
a recovery of about $75 \%$ in $\mathrm{KIC}$ when the microcapsule mass fraction was increased from $5 \%$ to $7.5 \%$ till reaching $10 \%$ concentration. Conclusions: In light of restoration fracture as one of the primary failure reasons, the novel self-healing dental composite may be promising to heal crack damages and to prolong the durability of the restoration clinically.

\section{INTRODUCTION}

Composite is a multiphase material that exhibits the properties of both phases (organic and inorganic) where the phases are complimentary, resulting in a material with enhanced properties. Resin composites are popular materials to fill tooth cavities due to their excellent esthetics and direct-filling capabilities. However, the durability of these restorations is limited, with half of all restorations failing in less than 10 years, and with fracture as one of the primary reasons for failure. It was reported that more than $25 \%$ of composite replacements were driven by some forms of fracture. Indeed, fracture of restorations was the main reason for failure in composite restorations in large cavities after 5 years of use ${ }^{[1,2]}$.

A main reason that composite restorations fail was suggested to be the formation and accumulation of micro-cracks, caused by factors including mastication forces and thermal stresses. They are hard to detect, and almost impossible to repair manually. If left untreated, this fatal deterioration leads to catastrophic failure of restorations, and hence, significantly shortens the duration of their service lives ${ }^{[3]}$.

Self-healing polymers were developed to recover the load-bearing capabilities after cracking. Self-healing composite with microcapsules containing a healing agent displayed healing efficacy. The microcapsules have an intact shell encapsulating a healing liquid inside. After incorporation of microcapsules into a polymer matrix, a propagating crack in the matrix would rupture the microcapsules, releasing the healing liquid into the crack planes, thus contacting the catalyst in the matrix, which triggers the polymerization of the healing liquid and autonomously heals the crack ${ }^{[4-6]}$.
In a pioneering study, dicyclopentadiene (DCPD) was encapsulated in a poly urea-formaldehyde (PUF) shell to form microcapsules. Grubb's catalyst, a transition metal carbine complex, was used in an epoxy matrix to trigger the polymerization of the released DCPD, which achieved a good self-healing efficiency. Since then, several other studies reported that microcapsules of various shell and healing liquid compositions, with potential applications ranging from micro-electronics to aerospace, as well as bone cement where effective rebonding of the crack was achieved, with the healed specimens reaching approximately $75 \%$ of the original fracture toughness ${ }^{[7-9]}$.

For dental use, efforts were made to incorporate DCPD-containing microcapsules and Grubb's catalyst into a composite, achieving a recovery of $57 \%$ of the original fracture toughness of composite. Another study tested the mechanical properties of dental resins with DCPD-containing microcapsules, showing that the use of microcapsules did not affect the mechanical performance of resin matrix. However, the literature revealed no further reports on the use of DCPD and Grubb's catalyst in dental materials, likely due to biocompatibility concerns. Toxicity from the self-healing agent inside the microcapsules as well as the catalyst present in the composite needs to be considered. The DCPD toxicity, Grubb's catalyst toxicity, and their high cost remain challenges in using them in dental composite $^{[10-12]}$.

The healing liquid should have a relatively low viscosity to flow and fill the cracks in the resin matrix. TEGDMA is flowable and has been used as a dental monomer with acceptable biocompatibility. Furthermore, TEGDMA can form a polymer via free-radical initiation by using a peroxide initiator and a tertiary amine accelerator. A usual dental tertiary amine accelerator, $N, N$-dihydroxyethyl- $p$-toluidine (DHEPT), has good solubility and stability in TEGDMA $^{[13,14]}$. 


\section{MATERIALS AND METHODS}

Synthesis of self-healing microcapsules: $30 \mathrm{ml}$ of healing liquid was prepared by adding $0.3 \mathrm{ml}$ $\mathrm{N}, \mathrm{N}$-Bis(2-hydroxyethyl)-p-toluidine

(DHEPT) to $29.7 \mathrm{ml}$ Triethylene glycoldimethacrylate (TEGDMA) monomer through which the DHEPT ratio was adjusted by $1 \%$ volume fraction of the total amount of TEGDMA, $0.325 \mathrm{gm}$ of poly (ethylene-alt-maleic) anhydride (EMA) (surfactant) was quantified by sensitive balance (WPS2100\Cl1 , Max2100gm, Min500mgm). then added to $13 \mathrm{ml}$ distilled water to give $13 \mathrm{ml}$ of $2.5 \%$ aqueous solution of EMA copolymer. The EMA does not dissolve easily in the water so a magnetic stirrer (Wise Stir - MSH 20D) at room temperature was used and the solution was prepared one day before the experiment to give a homogenous solution. The EMA solution was used as a surfactant to form an "oilin-water" emulsion ("oil" being the healing liquid, TEGDMA-DHEPT). Then the prepared EMA solution was mixed with $50 \mathrm{ml}$ distilled water in a $250 \mathrm{ml}$ round bottom glass flask. The flask was suspended in a water bath on which a homogenizer (Hielscher UP50H- Compact Lab Homogenizer) was mounted. Under agitation by the homogenizer at $300 \mathrm{rpm}$, the shell-forming materials were added which are as follows: urea $(1.25 \mathrm{~g})$, ammonium chloride $(0.125$ g) and resorcinol $(0.125 \mathrm{~g})$. Before adding the prepared healing liquid to the shell forming material the $\mathrm{pH}$ must be tested and adjusted in a $\mathrm{pH}$ scale from 2.7 to 3.5 , it was adjusted via drop-wise addition of $1 \mathrm{M}$ sodium hydroxide $(\mathrm{NaOH})$ solution. After increasing the agitation rate to 400rpm, the healing liquid was added to the flask. A stabilized emulsion of fine TEGDMA-DHEPT droplets was formed after $10 \mathrm{~min}$ of agitation. Then, $3.15 \mathrm{~g}$ of a $37 \%$ aqueous solution of formaldehyde was added, and the flask was sealed with aluminum foil to prevent evaporation. The temperature of the water -bath was raised to $55{ }^{\circ} \mathrm{C}$ and the shell material was isothermally polymerized for $4 \mathrm{~h}$ under continuous agitation. At this stage, the microencap- sulation process began through which ammonium chloride catalyzed the reaction of urea with formaldehyde to form PUF at the oil-water interface to develop the shell. The obtained microcapsules were rinsed with water and acetone repeatedly, vacuum-filtered, and air-dried for $24 \mathrm{~h}$ in a hood. The prepared microcapsules were examined by optical microscope (TE2000-S, Nikon, Japan) to examine the morphological structure of the capsule and to confirm the microencapsulation process proceeded appropriately.

Fabrication of experimental dental composite resin: Bisphenol A glycerolate dimethacrylate (BisGMA) and triethylene glycol dimethacrylate (TEGDMA) were mixed at 3:1 mass ratio to form the resin matrix ${ }^{[15] . ~ T h e ~ m o n o m e r ~ m i x t u r e ~ w a s ~ r e n-~}$ dered light-curable by adding $1 \%$ of photo-initiator Phenyl-bis 2,4,6-trimethylbenzoyl Phosphine oxide (BAPO). Then $0.5 \%$ by mass of benzoyl peroxide (BPO) was dissolved in the mixture. BPO serves as an initiator to react with the N,N-Bis(2hydroxyethyl)-p-toluidine (DHEPT) in the healing liquid to trigger the polymerization. Prior to addition of the microcapsule to the resin matrix, the microcapsule integrity must be confirmed. The microcapsules with different concentrations $(0,2.5,5,7.5,10)$ were added to the prepared resin matrix.

Silanation of the fillers: The 4\% 3-meth-acryloxypropyltrimethoxysilane silane (MPS) solution was used for proper wetting of the barium silicate filler. The amount of silane used for silanation was calculated by using the following equation ${ }^{[16-18]}$ :

$$
\mathbf{X}=(\mathbf{A} / \boldsymbol{\omega}) \mathbf{f}
$$

Where: $\mathrm{X}$ : is the amount of saline needed to obtain a minimum uniform coverage of the filler particles (in grams), A: is the surface area of the filler $\left(\mathrm{m}^{2} / \mathrm{g}\right), \omega$ : is the wetting surface of MPS $\left(83 \mathrm{~m}^{2} / \mathrm{g}\right)$, $\mathrm{f}$ : is the amount of fillers (g). After adding the silane to the filler, the fillers were left for several hours until complete dryness, then added to the resin ${ }^{[19]}$. Fillers were added to the resin matrix in order to 
reach a cohesive mass reliable for packing inside the mold. Barium boro aluminosilicate filler with a median particle size $1.45 \mu \mathrm{m}$ was added into the resin at a filler loading $70 \%$ by mass , the optimum amount of filler added was adjusted by using a sensitive balance and standardized to the rest of the specimens. Each specimen with different microcapsule percentage was placed inside a labeled bottle in order to begin specimen preparation.

Specimens' grouping: A total of 50 specimens were prepared for laboratory study. The specimens were divided according to capsules mass fractions of $0 \%, 2.5 \%, 5 \%, 7.5 \%$, and $10 \%$ into five groups $(\mathrm{n}=10)$. One control group and four experimental groups, then each group will be further subdivided into two subgroups $(\mathrm{n}=5)$ according to the testing method. (Flexural strength and fracture toughness).

\section{Scanning Electron Microscopic examination:}

Scanning was carried out for the composite specimens to examine the uniform distribution of the filler and the microcapsule through the matrix using Scanning Electron Microscope (Model Quanta 250 FEG (Field Emission Gun))attached with EDX Unit ( Energy Dispersive X-ray Analyses), with accelerating voltage $30 \mathrm{~K} . \mathrm{V}$. and magnification $14 \mathrm{x}$ up to 1000000 .

Flexural strength measurement: Five specimens for each group of different microcapsule concentrations $(0,2.5,5,7.5,10)$ were prepared. The composite paste was placed into a Teflon mold of $(25 \times 2 \times 2 \mathrm{~mm})$ ADA No.27 ${ }^{[20]}$ and covered with Mylar strips. Each specimen was photo-cured for $1 \mathrm{~min}$ for each open side of the mold. Their surfaces were made smooth by grinding prior to 3 point testing. Then the specimens were stored in distilled water at $37^{\circ} \mathrm{C}$ for 24 hours before testing. The flexural strength (in Mpa) was calculated from the formula ${ }^{[20] \text { : }}$

\section{$\sigma f=3 \mathrm{FL} / 2 \mathrm{bh}^{2}$}

Where: F: is the failure load $(\mathrm{N}), \mathrm{L}$ : is the distance between the supports in $\mathrm{mm}$, b: is the width of the specimen, $\mathrm{h}$ : is the height of the beam in $\mathrm{mm}$.
Fracture toughness measurement:_5 specimens for each group of different microcapsule concentrations $(0,2.5,5,7.5,10)$ were prepared using the single edge notched design (ASTM 399-83) ${ }^{[21]}$. A rectangular copper split mold with internal dimensions $(25 \mathrm{~mm}$ in length, $5 \mathrm{~mm}$ in width and $2.5 \mathrm{~mm}$ in thickness) was used, four molds were fabricated for different microcapsule concentrations. The mold was designed with a razor blade insert fixed into a slit in the middle of its long side and projecting in the mold with a length of $2.5 \mathrm{~mm}$ throughout the total thickness of the mold. This resulted in a 0.5 notch/depth ratio of the specimen. Before packing the composite mix, the mold was coated with a separating medium and allowed to dry for 20 minutes. The composite mix was packed in the mold against a celluloid matrix and glass slab placed on the bottom surface of the mold until the mold was filled, this was done over a vibrator to avoid air bubbles entrapment. The specimens were stored at $37^{\circ} \mathrm{C}$ for 24 hours in distilled water. The fracture toughness KIC (in Mpa. $\mathrm{m}^{1 / 2}$ ) was calculated according to the equation: ${ }^{[21,22]}$

$$
\mathrm{KIC}=\left[3 \mathrm{Pla}^{1 / 2} / 2 \mathrm{bw}^{2}\right] \times \mathbf{f}(\mathrm{a} / \mathrm{w})
$$

Where, KIC: is the fracture toughness in Mpa.m ${ }^{1 / 2}, \mathrm{P}$ : is the load at fracture in Newton, L: is the distance between the supports in $\mathrm{mm}$, a: is the crack length in $\mathrm{mm}, \mathrm{w}$ : is the width of the specimen in $\mathrm{mm}$, b: is the thickness of the specimen in $\mathrm{mm}$.

Self-healing efficacy measurement:_To test self-healing efficacy, the two halves of the specimen were placed back immediately following fracture into the mold which was originally used to make the same specimen to ensure a good contact of the two fractured planes. The reassembling step was done cautiously to avoid any dislodgement between the two fractured parts which may lead to change in the original notch length and disturb the healing mechanism. The healed specimen was placed in distilled water at $37^{\circ} \mathrm{C}$ for $24 \mathrm{~h}$. The healed specimen was tested again using the same flexural method to measure the healed fracture toughness, KIC-healed. The self-healing efficacy $(\eta)$ was assessed according to following equation: ${ }^{[14,23]}$ 


\section{$\eta=$ KIC-healed $\quad \mathbf{x 1 0 0}$ \\ KIC-virgin.}

\section{Statistical analysis}

One-way ANOVA was used to compare between more than two groups in non-related samples. Paired sample t-test was used to compare between two groups in related samples.

One-way ANOVA was used to compare between more than two groups in non-related samples. Paired sample t-test was used to compare between two groups in related samples.

The significance level was set at $\mathrm{P} \leq 0.05$. Statistical analysis was performed with IBM ${ }^{\circledR}$ SPSS ${ }^{\circledR}$ Statistics Version 20 for Windows.

\section{RESULTS}

Flexural strength: Mean Flexural strength of composite resin specimens with different microcapsule concentrations are presented in table (1) and plotted in figure (1),A statistical significant difference was found between $10 \%$ microcapsule concentration and all the tested microcapsules concentrations, however there was no statistical significant difference among the other tested microcapsules concentrations $(0 \%, 2.5 \%, 5 \%, 7.5 \%)$. The highest mean flexural strength value was found with (Concentration $0 \%)(80.30 \pm 4.51)$, whereas the lowest mean flexural strength value was found with (Concentration 10\%) $(58.99 \pm 4.02)(\mathrm{p}<0.001)$.

\begin{tabular}{|l|c|c|}
\hline \multicolumn{1}{|c|}{ Concentration } & Mean & SD \\
\hline Concentration 0\% & $80.30^{\mathrm{a}}$ & 4.51 \\
\hline Concentration $\mathbf{2 . 5 \%}$ & $78.75^{\mathrm{a}}$ & 2.06 \\
\hline Concentration 5\% & $76.82^{\mathrm{a}}$ & 2.56 \\
\hline Concentration $\mathbf{7 . 5 \%}$ & $75.60^{\mathrm{a}}$ & 4.01 \\
\hline Concentration $\mathbf{1 0 \%}$ & $58.99^{\mathrm{b}}$ & 4.02 \\
\hline p-value & $<\mathbf{0 . 0 0 1}^{*}$ & \\
\hline
\end{tabular}

Superscripts with different small letters indicate statistically significance difference within the same column. *; significant $(p \leq 0.05)$.

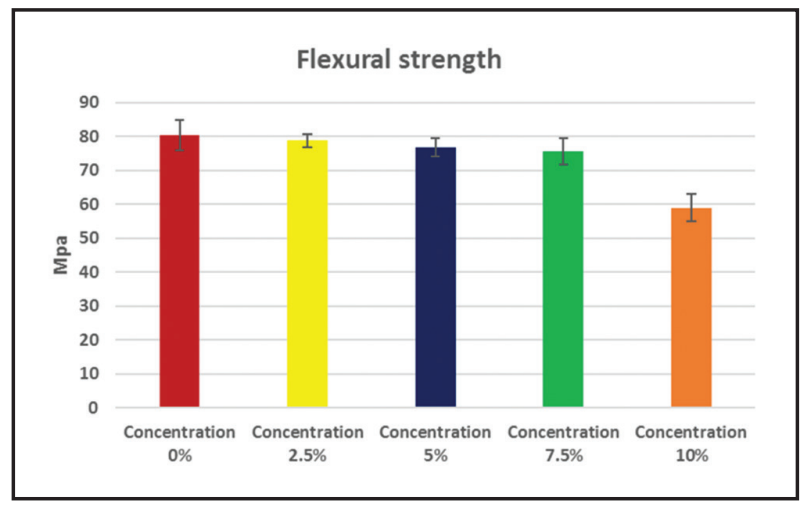

Fig. (1): Bar chart representing flexural strength with different microcapsule concentrations

Fracture toughness: Mean Fracture toughness values of the virgin and healed composite specimens among different concentrations are represented in table (2) and plotted in figure (2), the mean virgin fracture toughness at concentration $10 \%$ was significantly lower than the other groups. Increasing the microcapsule concentration to $10 \%$ reduces the mean virgin fracture toughness values from $(2.41 \pm 0.10)$ at Concentration $0 \%$ to $(0.67 \pm 0.04)$ at Concentration $10 \%$, while The highest mean Healed Fracture Toughness value was found with (Concentration 5\%) (1.08 \pm 0.19$)$, followed by (Concentration 7.5\%) $(0.99 \pm 0.16)$ and (Concentration 10\%) $(0.51 \pm 0.07)$, while the lowest mean Healed Fracture Toughness value was found with (Concentration 0\%) and (Concentration 2.5\%) $(0.00 \pm 0.00)$. The healed fracture toughness significantly increased from no healing at concentration $0 \%$ and $2.5 \%$ to maximum healing at concentrations $5 \%$ and $7.5 \%$.

Self healing efficacy: Mean self-healing efficacy values of healed resin composite specimens among different microcapsule concentrations are plotted in figure (3).The highest mean value of healing was found with (Concentration 10\%) $(75.95 \% \pm$ 7.78), followed by (Concentration 7.5\%) $(57.65 \% \pm$ $8.82)$, (Concentration $5 \%)(54.61 \% \pm 7.80)$. However, no healing was found with (Concentration $2.5 \%)$ and (Concentration 0\%) $(0.00 \pm 0.00)$. 


\begin{tabular}{|c|c|c|c|c|c|}
\hline \multirow{2}{*}{$\begin{array}{l}\text { Microcapsule } \\
\text { Concentrations }\end{array}$} & \multicolumn{2}{|c|}{ Virgin } & \multicolumn{2}{|c|}{ Healed } & \multirow[b]{2}{*}{ p-value } \\
\hline & Mean & SD & Mean & SD & \\
\hline Concentration $0 \%$ & $2.41^{\mathrm{aA}}$ & 0.10 & $0.00^{\mathrm{cB}}$ & 0.00 & $<0.001 *$ \\
\hline Concentration $2.5 \%$ & $2.29^{\mathrm{aA}}$ & 0.18 & $0.00^{\mathrm{cB}}$ & 0.00 & $<0.001 *$ \\
\hline Concentration $5 \%$ & $1.98^{\mathrm{aA}}$ & 0.17 & $1.08^{\mathrm{aB}}$ & 0.19 & $<0.001 *$ \\
\hline Concentration $7.5 \%$ & $1.72^{\mathrm{aA}}$ & 0.06 & $0.99^{\mathrm{aв}}$ & 0.16 & $<0.001 *$ \\
\hline Concentration $10 \%$ & $0.67^{\mathrm{bA}}$ & 0.04 & $0.51^{\mathrm{bB}}$ & 0.07 & $0.002 *$ \\
\hline p-value & \multicolumn{2}{|c|}{$<0.001 *$} & \multicolumn{2}{|c|}{$<0.001 *$} & \\
\hline
\end{tabular}

Superscripts with different lower-case subscripts indicate statistically significance difference within the same column. Superscripts with different upper-case subscripts indicate statistically significance difference within the same row $*$; significant $(p \leq 0.05)$.

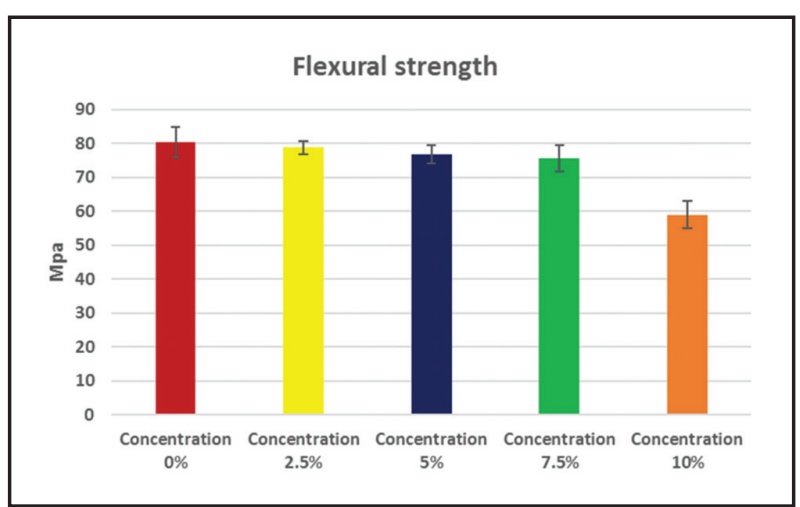

Fig. (2): Bar chart representing the virgin and healed fracture toughness among different microcapsule concentration

\section{Scanning Electron Microscope:}

The microcapsule was examined by Scanning Electron Microscope which revealed that the microcapsules had numerous PUF nanoparticles attached to a smooth shell surface to form a rough shell. The smooth shell surface appeared to be dense without voids or pores. Fractured and healed composite

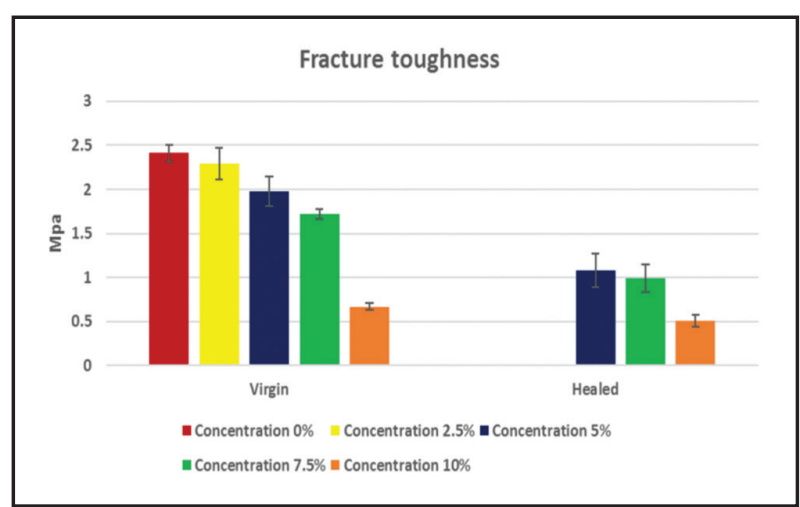

Fig (3): Line chart representing Self-healing efficacy among different microcapsule concentrations

specimens with different microcapsule concentrations were examined by scanning electron microscope. Scanning electron micrograph revealed that the surfaces of the composite resin specimens show uniform distribution of the fillers and microcapsules with in the resin matrix. Moreover, the specimens show specific structures related to the healing process figure (4). 


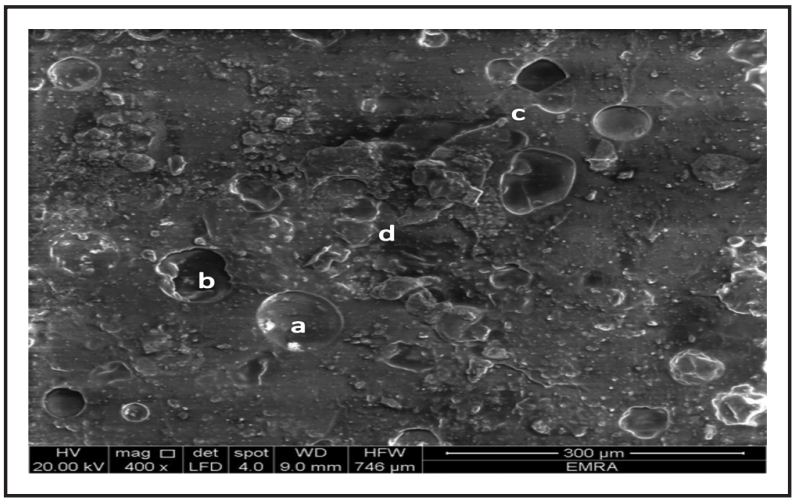

Fig. (4): Scanning electron micrograph of fractured plane of healed composite specimen.(a) intact microcapsules indicating that some of them did not undergo fracture,(b) Empty microcapsules capsules denoting the release of the healing liquid, (c) Step tails originating from the fractured microcapsules. (d) Numerous irregularly polymerized shaped films in many different locations on the fracture surface indicating the successful release of TEGDMA from microcapsules and its polymerization to bond the cracked planes together.

\section{DISCUSSION}

In the current study, TEGDMA -DHEPT containing microcapsules were synthesized and were incorporated into the dental resin. The composite containing the microcapsules demonstrated successful healing, with substantial recovery of load bearing capability. These microcapsules with a healing liquid of TEGDMA plus $1 \%$ DHEPT surrounded by a PUF shell, were manufactured through an in situ polymerization technology an oil-in-water emulsion.

The capsules prepared are in the micro scale ranging from $24-70 \mu \mathrm{m}$, these microcapsules prepared are shown to satisfy the requirements for use in self-healing materials including processing, serviceability and efficient in situ rupture for delivery of the healing agent. Also It must be mentioned that increasing the size of the capsule by using super enlarged macro-capsule will become weak spots into the composite as it will affect the resin matrix cross linking thus reducing its mechanical properties. Moreover, increasing the size of the capsule will cause broad size distribution of the healing liq- uid so it will decrease the homogeneity inside the capsule $^{[15,24-26]}$.

The prepared microcapsule was examined by optical microscope, to examine the morphological structure of the capsule and to confirm the encapsulation process. The microscopic picture reveals dark outer shell and inner bright core material; this phenomenon was attributed to the two different refractive indices of the PUF shell and the healing liquid inside. Moreover, this difference in the refractive indices confirm the absence of premature polymerization of the healing also this indicates that the TEGDMA was success-fully encapsulated by the PUF shell with negligible loss of healing liquid. Furthermore, SEM for a representative microcapsule, showed numerous PUF nanoparticles attached to the shell surface which has high surface energy transferring it from smooth to rough surface. The rough shell surface is more recommended than the smooth shell surface, as it increases the incorporation of the microcapsule within the resin matrix. Also microcapsule wall with nanoparticle deposit is of vital importance in obtaining a mechanical interlock between the microcapsule and resin matrix. An interlocking interface would help the microcapsule to be ruptured when a crack propagating in the resin matrix hits the microcapsule. In contrast, with a smooth interface without interlock, the resin matrix crack may go around the microcapsule and not rupture it, without releasing the healing liquid to heal the crack ${ }^{[14,27]}$.

The present study investigated the effect of incorporation of the new TEGDMA-DHEPT-in-PUF micro-capsules into an experimental dental resin composite on its mechanical properties and the evaluation of its self-healing efficacy. Mechanical properties are important for composite in load-bearing restorations. Incorporation of microcapsules into the composite to achieve self- healing ability must not sacrifice the original mechanical properties of the composite. 
The results of flexural strength in the present study revealed that there was a significant difference between all concentrations, the $10 \%$ concentration has the lowest flexural strength value while the $0 \%$ concentration has the highest flexural strength value. This could be attributed to lack of interaction in terms of bonding between the microcapsules and the continuous matrix phase ${ }^{[28]}$. In the present study, addition up to $7.5 \%$ microcapsules into the composite did not decrease the flexural strength remarkably. In addition, the present study demonstrated that there was a significant reduction in the flexural strength at $10 \%$ microcapsules, such observation still supporting the above explanation that stated the effect of the presence of microcapsules in the cross linked resin matrix ${ }^{[28,29]}$.

Increasing the microcapsule concentration to $10 \%$ reduces the mean virgin fracture toughness values from $(2.41 \pm 0.10)$ at Concentration $0 \%$ to $(0.67 \pm 0.04)$. The majority of previous studies showed that the incorporation of self-healing microcapsules into a polymer matrix increased the KIC-virgin, compared to that without microcapsules ${ }^{[30,33]}$. However, these previous studies used epoxy matrices, this was different from the present study as the composite used was different from epoxy because the resin was filled with glass fillers. Indeed, a previous study added 5\% self-healing microcapsules to a dental composite containing $45 \%$ resin and 55\% glass fillers, and the KIC-virgin was neither increased nor decreased after the microcapsule addition ${ }^{[28]}$. Such studies was disagreed with the finding of the present study which showed that KIC-virgin was not changed significantly when adding up to $7.5 \%$ of microcapsules; but at $10 \%$ microcapsules, KIC-virgin was significantly reduced.

The results of the present study were consistent with other studies which showed the higher microcapsule concentration, the higher the healing effect. Furthermore, the findings of the present study showed that the lowest healed fracture toughness was in $10 \%$ microcapsule concentration, followed by $7.5 \%$, followed by $5 \%$, this supported the above concept which illustrated the reversal effect of increasing the microcapsule concentration on the cross link density of the polymer matrix [28,29] . The self-healing efficacy increased to a recovery of about $75 \%$ in KIC when the microcapsule mass fraction was increased from $5 \%$ to $7.5 \%$ till reaching $10 \%$ concentration. A lower recovery at $5 \%$ microcapsules was due to the insufficient dosage of the microcapsules, leading to insufficient quantity of the released healing agent to cover the broken planes ${ }^{[28]}$ The better healing effect deriving from higher microcapsule concentrations may be explained by more healing agent release, resulting in re-bonding of the cracked planes, Moreover, this also explain the finding that no healing occur in the $2.5 \%$ concentration specimen. Therefore, for the experimental dental composite of the current study the $7.5 \%$ microcapsule concentration appeared to be optimal, achieving the highest KIC-healed, without compromising the KIC-virgin and without compromising the flexural strength.

\section{CONCLUSION}

Within the limitations of the present study, the following was concluded:

1. Incorporation of microcapsules in composite resin can inevitably affects the mechanical properties by decreasing the flexural strength and fracture toughness.

2. Incorporating of $7.5 \%$ microcapsule concentration into the composite resin did not compromise the flexural strength and virgin fracture toughness, compared to that without microcapsules.

\section{REFERENCES}

1. Nash RW. Direct composite resin restorations for today's practice. Dent Today 2013; 32: 114, 116, 18.

2. Ilie N., Hickel R., Resin composite restorative materials. Aust Dent J 2011; 56: 59-66.

3. Baran GR, Boberick KG, McCool JI. Fatigue of restorative materials. Crit Rev Oral Biol Med 2001; 12: 350-60. 
4. Yuan YC, Yin T, Rong MZ, Zhang MQ. Self healing in polymers and polymer composites. Concepts, realization and outlook: A review. Express Polymer Letters. 2008; 2: 238-50.

5. Yuan L, Liang G, Xie JQ, Li L, Guo J. Preparation and characterization of poly (urea-formaldehyde) microcapsules filled with epoxy resins. Polymer. 2006; 47:5338-49.

6. Esser-Kahn AP, Odom SA, Sottos NR, White SR, Moore JS. Triggered release from polymer capsules. Macromolecules. 2011; 44:5539-53.

7. Murphy EB, Wudl F. The world of smart healable materials. Prog Polym Sci 2010; 35: 223-51.

8. Yang Y, Urban MW. Self-healing polymeric materials. ChemSoc Rev 2013; 42: 7446-67.

9. Dailey MM, Silvia AW, McIntire PJ, Wilson GO, Moore JS,White SR. A self-healing biomaterial based on free-radical polymerization. J Biomed Mater Res A 2014; 102(9): 3024-32.

10. Then S, Neon GS, kasim NH. Performance of melaminemodified urea-formaldehyde microcapsules in a dental hostmaterial. J Appl Polym Sci 2011; 122: 2557-62.

11. Jandt KD, Sigusch BW. Future perspectives of resin-based dental materials. Dent Mater 2009; 25: 1001-6.

12. Caruso MM, Delafuente DA, Ho V, Sottos NR, Moore JS, WhiteSR. Solvent-promoted self-healing epoxy materials. Macromolecules 2007; 40: 8830-2.

13. Ouyang X, Huang X, Pan Q, Zuo C, Huang C, Yang X, et al. Synthesis and characterization of triethylene glycoldimethacrylate nanocapsules used in a self-healing bonding resin. J Dent 2011; 39: 825-33.

14. Wu J,Weir MD, Zhang Q, Zhoud CH, Melo MA, Xu HK. Novel self-healing dental resin with microcapsules of polymerizable triethylene glycol dimethacrylateand N,N-dihydroxyethyl-p-toluidine. Dent. Mater. 2015; 2668: 1-14 .

15. Wu J., Weir MD., Melo MAS., Strassler HE., Effects of water-aging on self-healing dental composite containing microcapsules .J DenT.2016; 47: 86-93.

16. Karabela MM, Sideridou ID. Effect of the structure of silane coupling agent on sorption characteristics of solvents by dental resin-nanocomposites. Dent Mater. 2008; 24:1631-1639.

17. Joseph M. Antonucci, Sabine H. Dickens, Bruce O. Fowle ,Hockin H. K. Xur, and Walter G. McDonough . Chemistry of Silanes: Interfaces in Dental Polymers and Composites1 J. Res. Natl. Inst. Stand. Technol. 2005;110: 541-558 .

18. Atai M, Pahlavan A, Moin N. Nano-porous thermally sintered nano silica as novel fillers for dental composites. Dent Mater. 2012;28:133-145.
19. Venhoven B.A.M, A. J. de Gee, Werner A. and Davidson CL. Silane treatment of filler and composite blending in a one-step procedure for dental restoratives. Biomater.1994;15 (14): 1152-115.

20. American National Standard. American Dental Association Specification no.27 for Resin-based filling materials; 1993.

21. ASTME399-83 (1983). Standard test method for planestrain fracture toughness of metallic materials.

22. Fujishima A, and Ferracane JL. Comparison of four modes of fracture toughness testing for dental composites. Dent Mater. 1996;12:38-43.

23. Wool RP, O'Connor KM. A theory of crack healing in polymers. J App Physics. 1981; 52:5953-63.

24. Keller M.W., Sottos N.R., Mechanical properties of microcapsules used in a self healing polymer, Exp. Mech. 2006; 46: 725-733.

25. Kessler M.R., Sottos N.R.,White S.R., Self-healing structural composite materials, Compos. A: Appl. Sci. Manuf. 2003; 34: 743-753.

26. BaLazs A.C, Modeling self-healing materials, Mater. Today 2007; 10: 18-23.

27. Wu JL, Weir MD, Melo MAS, Xu HHK. Development of novel self-healing and antibacterial dental composite containing calcium phosphate nanoparticles. J of Dent. 2015; 43:317-326.

28. Huyang G., Debertin A.E., Sun J., Design and development of self-healing dental composites. J.Mater Des. 2016; 94: 295-302.

29. Wertzberger BE, Steere JT, Pfeifer RM, Nensel MA, Latta MA, Gross SM. Physical Characterization of a SelfHealing Dental Restorative Material. J App Polymer Science, 2010; 118: 428-434.

30. Yuan L, Huang S, Gu A, Liang G.,Chen F., Y. Hu, et al., A cyanate easter/microcapsule system with low cure temperature and self-healing capacity, Compos. Sci. Technol. 2013; 87: 111-117.

31. Brown E.N., Sottos N.R., White S.R., Fracture testing of a self-healing polymer composite. Exp. Mech. 42 2002; 42: 372-379.

32. Brown E.N., White S.R., Sottos N.R., Microcapsule induced toughening in a self healing polymer composite, $\mathrm{J}$. Mater. Sci.2004; 39: 1703-1710.

33. Keller M.W., White S.R., Sottos N.R., A self-healing poly(dimethyl siloxane)elastomer, Adv. Funct. Mater. 2007; 17: 2399-2404 